\title{
MAKNA HIDUP DALAM KASIH \\ MENURUT RASUL PAULUS BERDASARKAN ROMA 12:9-21
}

Estherlina Maria Ayawaila

estherlinamariaayawaila@sttab.ac.id

\begin{abstract}
Romans are letters written by the Apostle Paul addressed to the church in Rome. One of the purposes of this letter is that in conveying love you have the correct method so that love can be done. The duty of believers is to convey love to those who have not done love like the Lord Jesus did. Problems to love can arise from a lack of understanding about love, understanding but not doing or starting to degrade the meaning of love in believers. Therefore this paper tries to remind again about the warmth of love for believers. In writing this scientific work the writer will explore how the meaning of life in love according to the Apostle Paul based on Romans 12: 9-21. To deepen the study of the writer uses the writing method which looks at the meaning of the right life in doing love especially in Romans 12: 9-21. So that this scientific work is easy to understand at the end, write a practical application in loving.
\end{abstract}

Keywords: Meaning, Life and Love.

Abstraksi: $\quad$ Surat Roma adalah Surat yang ditulis oleh Rasul Paulus yang ditujukan kepada jemaat yang ada di Roma. Salah satu tujuan surat ini agar dalam menyampaikan kasih memiliki metode yang benar agar kasih tersebut bisa dilakukan. Tugas orang percaya adalah menyampaikan kasih kepada orang yang belum melakukan kasih seperti yang Tuhan Yesus lakukan. Problematika untuk mengasihi dapat muncul dari ketidakpahaman tentang kasih, paham namun tidak melakukan atau mulai terdegradasinya makna kasih dalam diri orang percaya. Oleh karena itu tulisan ini mencoba untuk mengingatkan kembali tentang kehangatan kasih bagi orang percaya. Dalam penulisan karya ilmiah ini penulis akan menggali bagaimana makna hidup dalam kasih menurut Rasul Paulus berdasarkan Roma 12:9-21. Untuk memperdalam kajian penulis menggunakan metode penulisan yang melihat bagaimana makna hidup yang benar dalam melakukan kasih khususnya dalam Roma 12:9-21. Agar karya ilmiah ini mudah dimengerti pada bagian akhir dituliskan aplikasi praktis dalam mengasihi.

Kata Kunci: Makna, Hidup dan Kasih.

\section{LATAR BELAKANG MASALAH}

Berbicara masalah hidup dalam kasih adalah panggilan hidup manusia. Panggilan manusia yang secara berangsur sehingga disadari itu merupakan landasan bagi panggilan mulia, yang disampaikan oleh yang mahakuasa kepada manusia untuk menjalin ikatan perjanjian, yaitu untuk menjadi umatNya, karena kesediaan yang menguasai semesta untuk menjadi Allahnya bahkan menjadi Bapanya, dalam sang puteranya, Yesus Kristus. Sekaligus disadarinya, bahwa arti hidupnya tidak diperoleh hanya dari pribadinya sendiri, 
sebagai manusia belaka, melainkan dan terutama dalam hubungannya dengan yang menciptakannya, yang melandasi seluruh panggilan hidupnya sebagai manusia. ${ }^{1}$ Margana mengatakan dalam bukunya bahwa:

Hidup adalah perjalanan yang harus diselesaikan dan disaat jatuh ingin segera bangun, disaat berat ingin tetap kuat,disaat sakit ingin selalu bertahan, disaat ada penolakan ingin terus maju berjuang. Paulus sungguh Rasul Kristus yang fenomenal dengan semangat juang tinggi. Perjalanan hidup Paulus memberi gambaran bagi manusia bahwa seluruh hidup dengan penuh liku-liku yang dialami mengungkapkan totalitas perjuangannya hingga sampai pada tujuan. ${ }^{2}$

Penulis simpulkan bahwa hidup harus tegak teguh dalam hal apapun tidak boleh menyerah menjalani hidup ini, sekalipun jatuh bangun harus bisa berdiri diatas kebenaran. Lewatilah hari demi hari dengan penuh suka cita dan disertain andalkan Tuhan untuk menjalani hidup ini dan percayalah bahwa pertolongan dari Tuhan Tidak pernah meninggalkan orang yang mengandalkan Dia. Kasih artinya secara formal akan dibatasi oleh ruang dan waktu yang dapat di raih dengan cara, bersihkan diri, optimis, serta sirami dan semaikan diri dengan kasih sayang. ${ }^{3}$ Kasih tidak kopromi dengan dosa tetapi terlebih dahulu mengkedepankan Tuhan Yesus dalam segala hal, sehingga kasih sayang itu tidak menyimpan dari kebenaran.

Kasih sayang juga berarti aset. Aset mengandung arti bekal. Bekal yang harus dijaga dan dikembangkan agar menghasilkan apa yang orang tersebut inginkan. Ibarat sebuah mobil, tentunya seseorang harus menjaga keadaan bahan bakar. Jangan sampai seseorang itu kehabisan bahan bakar, sementara perjalanan yang akan di tempuh begitu panjang. ${ }^{4}$ Dapat disimpulkan bahwa bukan hanya itu saja juga ada usaha untuk menjaga, sehingga kasih itu menghasilkan sesuai apa yang Tuhan inginkan dan sesuai dengan kebenaran Firman Tuhan karena dalam hidup ini bukan hanya di jalani 1 atau 2 hari saja tentunya panjang sampai kedatangan Tuhan Yesus ke dua kalinya.

Hidup adalah anugrah dan kebahagiaan, dan cinta dalam kasih yang tulus adalah kesempurnaan hidup. ${ }^{5}$ Jadi penulis simpulkan bahwa dalam kesengsaraan mampu memberi kesejukan dan anugrah untuk menjalani hidup lebih berarti. Cinta memang hidup dalam kasih, termasuk dalam penderitaan dan kesusahan. Dalam menjalani hidup dalam kasih

\footnotetext{
${ }^{1}$ Mardiatmadja, Hidup Dalam Roh (Yokyakarta: Kanisius, 1982), 8

2 P. Tri Margana, 50 Kalimat Inspiratif Rasul Paulus Untuk Pengembangan Diri (Yogyakarta: Kanisius, 2009), V

${ }^{3}$ Sumartono, Komunikasi Kasih Sayang, (Jakarta: Pt Elex Media Komputindo, 2004), 139

${ }^{4}$ Sumartono, Komunikasi Kasih Sayang, 128

${ }^{5}$ Nistain Odop, 55 Wasiat Cinta Dan Kehidupan, (Jakarta : PT. Elex Media Komputindo, 2013), 
ibarat sekumpulan kesempatan untuk orang percaya. Indrayana mengatakan dalam bukunya bahwa: "Manusia tidak pernah tahu apa yang akan terjadi dalam hidup ini lima sepuluh tahun mendatang. Saya tidak pernah dapat mengatakan apakah saya masih hidup atau tidak setelah selesai tulisan ini". ${ }^{6}$ Dapat disimpulkan bahwa waktu ada kesempatan untuk dapat menjalani hidup ini, maka sebagai orang percaya dapat mempergunakan waktu yang ada dengan baik sebab hari demi hari manusia tidak tahu kapan meninggal dunia kembali kepada Bapa di sorga karena tidak ada 1 orang pun yang tahu kapan hari perhentiannya yang Tuhan tentukan. ${ }^{7}$

Dalam hal ini penulis simpulkan bahwa jalanilah hidup dengan baik jangan hanya hidup mengutamakan apa yang disenangi hati melainkan ada panggilan tanggungjawab yang seharusnya yang sudah Allah percayakan kepada umatnya yaitu melakukan kasih itu tak ada batasnya baik itu kepada sesama terlebih kepada Tuhan. Olla mengatakan dalam bukunya bahwa:

Arti Panggilan secara umum: menunjuk pada kenyataan bahwa melalui babtisan semua orang kristiani dipanggil menjalani tugas pengutusan (misi) dan karena itu semua menjadi pewarta (misionaris). Maka menjadi kristiani sama menjadi misionaris. Kesatuan dengan hidup Kristus yang terjadi dalam pembabtisan memungkinkan setiap orang terbabtis mengambil bagian dalam tugas Kristus dan misinya bagi keselamatan dunia. Maka semua yang dipanggil menjadi kristiani pada saat yang sama juga adalah misionaris. ${ }^{8}$

Dengan demikian hal ini misi dan misionaris dalam arti umum di atas penulis simpulkan bahwa tertunjuk kepada orang-orang yang sudah menerima Kristus sebagai juruselamatnya maka dalam hal itu tidak ada alasan orang yang sudah dipanggil untuk tidak menjadi saluran berkat bagi semua orang. Poulinus mengatakan dalam bukunya bahwa:

Arti panggilan khusus: panggilan khusus ini bukan sesuatu yang berlainan dengan panggilan umum yang telah dibahas di atas. Panggilan khusus sebagai misionaris justru berbasis pada panggilan umum, yang dibangun atas babtisan. Panggilan khusus ditandai oleh rahmat khusus yang dikaruniakan Roh Kudus demi pelayanan sesama. ${ }^{9}$

Penulis simpulkan bahwa panggilan khusus itu panggilan yang benar-benar berkenan kepada Allah yang dikhususkan untuk bertekad mewartakan injil kepada orang-

${ }^{6}$ Stefanus Indrayana, Best Live Menjalani Hidup Bahagia Penuh Makna (Jakarta: PT. Elex Media Komputindo, 2007), Vii-Viii

${ }^{7}$ Legiyani Dewi, Kumpulan Cerpen Kisah-Kasih Di Dunia, (Jakarta :Guepedia Publisher, 2017), 97

${ }^{8}$ Paulinus Yan Olla, Dipanggil Menjadi Saksi Kasih, (Yogyakarta: Kanisius, 2008), 41

${ }^{9}$ Olla, Dipanggil Menjadi Saksi Kasih, 41 
orang yang belum mengenal Yesus Kristus, sehingga banyak jiwa-jiwa datang kepada Yesus Kristus. Dalam dokumen Konsili Vatikan II atau tempat kediaman Paus di Roma, pemerintahan dan kekuasaan Paus diakui bahwa gerakkan dan ketertarikan untuk mewartakan Injil pada semua orang yang jauh dari Kristus merupakan suatu panggilan khusus. Ditegaskan dalam dokumen itu bahwa sekalipun semua murid Kristus mempunyai misi untuk mewartakan iman akan Kristus, Kristus Tuhan telah secara khusus memanggil orang-orang dari antara para murid-Nya untuk diutus sebagai misionaris (Markus 3:13). ${ }^{10}$

Dengan demikian penulis simpulkan bahwa Allah memanggil orang-orang yang di kehendakinya untuk diutus dan tidak ada kata penolakan sebab sudah jadi tugas tanggungjawab yang Tuhan percayakan kepada orang yang dikhususkannya demi membawa jiwa-jiwa yang jauh kepadaNya membawa kepada Tuhan untuk diselamatkan. Pratinjau mengatakan bahwa: "Ditegaskan pula perlunya orang menjawab panggilan dengan adanya komitmen dalam menyambut serta menjawabnya. Mengenai hal itu dikatakan sebagai berikut: dalam aneka bentuk kehidupan serta tugas satu kesucian yang sama diamalkan oleh semua, yang digerakkan oleh Roh Allah, dan yang mematuhi suara Bapa serta berwujud kepada Allah Bapa Roh dan kebenaran, mengikuti Kristus yang miskin, rendah hati dan memanggul salib-Nya, agar mereka pantas ikut menikmati kemuliaan-Nya". ${ }^{11}$ Artinya mengikut panggilan itu adalah suatu komitmen orang percaya yang telah mematuhi dan taat akan kebenaran Allah dan ikut serta untuk memikul salibNya. Penjelasan ini ditegaskan kembali oleh Paulinus mengatakan bahwa:

Panggilan itu tidak menunjuk ke tempat yang tidak baik, tetapi pada apa yang utama untuk menempatkan misi sebagai hal utama dalam diri pribadi terpanggil. Panggilan khusus sebagai misionaris berlangsung menurut makna hidup dan panggilan para Rasul. Panggilan seperti itu melibatkan seluruh hidup misionaris dalam komitmennya untuk mengabdikan diri sepenuhnya bagi misi dalam suatu pemberian diri sepenuhnya bagi misi bagi suatu pemberian diri tanpa batas dalam hal tenaga maupun waktu. ${ }^{12}$

Dalam hal ini penulis simpulkan bahwa totalitas penyerahan diri hendak menjadi misionaris untuk sepanjang hidupnya bekerja sebagai misionaris yang hidup benar-benar seperti misionaris yang sesungguhnya. Menyangkut panggilan khusus mesioner dengan mengikuti apa yang ditekankan Poulinus menegaskan bahwa panggilan itu tidak menunjuk pada tempat yang tidak benar, tetapi pada yang didahului dan diutamakan pada sasaran misi sebagai hal utama dalam diri pribadi terpanggil itu.

\footnotetext{
${ }^{10}$ Olla, Dipanggil Menjadi Saksi Kasih,41-48

${ }^{11}$ Darminta J, Penegasan Panggilan, (Yogyakarta : Kanisius, 2006), 12

${ }^{12}$ Olla, Dipanggil Menjadi Saksi Kristus (Yogyakarta: Kanisius, 2008), 46
} 
Pada masa kini Berdasarkan banyak orang percaya masih belum mengerti dan menerapkan hidup dalam kasih, dan masih banyak yang memiliki motivasi dalam melayani Tuhan dengan menuntut imbalan. Berdasarkan gambaran di atas membuktikan bahwa tidak semua orang mengasihi sesuai yang diingin oleh Tuhan dan sesama. Setelah memahami latar belakang di atas, maka dapat dirumuskan pertanyaan apa makna hidup dalam kasih menurut Rasul Paulus berdasarkan Roma 12:9-21?. Untuk mejawab hal tersebut perlu dilakukan kajian Biblikal-Teologis terhadap teks Roma 12:9-21.

\section{LATAR BELAKANG SURAT ROMA}

Drane berkata bahwa: "Surat Roma lebih baik dipahami sebagai suatu uraian yang disususn lebih teratur terhadap beberapa tema yang dibahas Paulus dalam surat Galatia dan 1-2 korintus". ${ }^{13}$ Mengapa demikian karena dalam surat Roma membahas tema-tema yang telah dicantumkan Rasul Paulus dalam tulisan-tulisannya yang lain yaitu kepada jemaat di Galatia dan Korintus, sehingga jika dilihat maka sangatlah sistematis.

Surat Roma ditulis oleh Rasul Paulus dengan tenang dan tanpa tergesa-gesa sehingga jika diteliti maka sangat teologis dan inti dari pembahasannya mengenai keselamatan di dalam Yesus Kristus. Hakh berkata bahwa: "Buah pemikiran Paulus dalam surat ini (Roma) dipikirkan secara matang, sehingga surat ini (Roma) ditulis dalam waktu yang lama". ${ }^{14}$ Penulis mengambil kesimpulan bahwa surat Roma yang sistematis itu karena ditulisnya dengan ketelitian sehingga teologisnya sangat mendalam bagi para sarjana dari masa ke masa. End berkata bahwa: "Surat Roma ditulis di Korintus (15:32), agaknya pada akhir perjalanan Paulus ketiga (15:25), menjelang awal musim pelayaran di wilayah laut tengah". ${ }^{15}$ Dalam penulisan surat Roma ini diperkirakan sekitar tahun 57 M karena keadaan Paulus pada saat itu digambarkan dalam Kisah Para Rasul 20:2-3, bahwa ternyata pada waktu itu orang-orang Yahudi bermaksud membunuh dia, sehingga ia terpaksa membantalkan pelayanan ke Siria dan mengambil jalan darat ke Filipi. Drane berkata bahwa: "Dalam surat Roma, Paulus tidak hanya menyiapkan diri bagi kunjungannya ke ibu kota kerajaan, ia juga memperhalus beberapa pemikirannya tentang keselamatan. ${ }^{16}$ Artinya bahwa surat ini adalah teologi Paulus yang dicantumkan dengan secara rinci mengenai keselamatan bukan melalui hukum Taurat tetapi melalui Yesus Kristus, agar jemaat yang membaca mengerti tentang keselamatan yang Tuhan berikan.

\footnotetext{
${ }^{13}$ John Drane, Memahami Perjanjian Baru (Jakarta: BPK Gunung Mulia, 2011), 368

${ }^{14}$ Samuel Benyamin Hakh, Perjanjian Baru (Bandung: Bina Media Informasi, 2010), 201

${ }^{15}$ End, Tafsiran Surat Roma, 3

${ }^{16}$ Drane, Memahami Perjanjian Baru,369
} 
Hakh berkata bahwa: "Surat Roma adalah surat terakhir yang ditulis Paulus di kawasan timur. Menurut Kisah Para Rasul 20:3, Paulus tinggal selama tiga bulan di Akhaya (Korintus) di sana ia dengan tenang menulis surat ini kepada jemaat yang ada di Roma". ${ }^{17}$ Jadi penulis menyimpulkan bahwa Rasul Paulus menulis surat Roma di Akhaya karena ada rencana gelap dari pihak Yahudi untuk membunuhnya sehingga ia menyingkirkan ke Akhaya di Korintus (Kis. 20:2-3). Ini menunjukkan bahwa begitu prihatin Paulus kepada jemaat yang ada di Roma agar tetap mempertahankan imannya dalam Kristus Yesus sebagai juruselamat manusia. Jika setiap orang membaca kitab Roma maka akan menemukan tulisan-tulisan yang sederhana dan teologis yang mendalam. Jaffray juga menjelaskan dalam bukunya bahwa: "Surat Roma dapat diibaratkan sebuah tambang batu intan, yang semakin dalam digali dan ditambang, semakin banyak dihasilkan intan-intan yang murni, indah, dan tidak ternilai harganya". ${ }^{18}$ Artinya semakin banyak dibaca buku Roma ini, semakin banyak mengetahui isinya dan lebih mengenal apa yang Tuhan mau dalam hidup ini.

Setiap tulisan pasti mempunyai tujuan masing-masing, oleh karena itu dalam surat Roma ini Hagelberg berkata bahwa: "Maksud dan tujuan surat Roma dijelaskan dalam pasal 15:22-25, yaitu Paulus memberitahu mereka bahwa ia ingin mengunjungi mereka di Roma. Pasal 15:24 menceritakan suatu maksud yang lain yaitu Paulus menghadapkan pertolongan mereka agar menuju ke Spanyol". ${ }^{19}$ Dalam hal ini Rasul Paulus merindukan jemaat di Roma untuk bertemu dengan mereka agar berbicara tentang Injil secara empat mata artinya bahwa berbicara secara langsung. Pembicaraan yang dilakukan secara langsung itu akan menimbulkan keterharuan kepada Jemaat Roma sehingga kemungkinan besar akan membantu Paulus untuk memberitakan Injil di Spanyol. Untuk memperoleh apa yang diharapkannya itu, Rasul Paulus menjelaskan injil Kristus baik murka Allah yang mengancam manusia maupun kebenaran Allah yang dianugrahkan untuk menyelamatkan setiap orang percaya. ${ }^{20}$

Memberitakan kemurkaan Allah yang bernyala-nyala kepada manusia yang tidak percaya Kristus adalah ancaman dan juga hukuman yang akan dinikmati oleh orang tersebut, dan ini adalah kutukan ketika manusia tidak menerima Kristus, sedangkan yang menerima Kristus adalah kebahagiaan yang Tuhan anugrahkan kepada manusia untuk menghidupi kehidupan yang baru bersama Kristus.

\footnotetext{
${ }^{17}$ Hakh, Perjanjian Baru, (Bandung: Bina Media Informasi, 2010), 201

${ }^{18}$ R.A. Jaffray, Tafsiran Surat Roma, (Bandung: Kalam Hidup, 2007), 14

${ }^{19}$ Dave Hagelberg, Tafsiran Roma, (Bandung: Kalam Hidup, 2013), 11

${ }^{20}$ Hagelberg, Tafsiran Roma, 11
} 


\section{Budaya Jemaat Roma}

Melihat budaya, jemaat roma menganut paham budaya helenisme, yang berbicara mengenai bahasa Yunani. Stambaugh berkata dalam bukunya bahwa: "Jemaat Roma sampai pada abad ke $2 \mathrm{M}$, merupakan sebuah komunitas helenisme, yang berbicara dalam bahasa Yunani dan mempertahankan hubungan yang erat dengan jemaat-jemaat Kristen Timur". ${ }^{21}$ Penulis simpulkan bahwa jemaat mula-mula di Roma memakai tradisi Yunani, Yahudi, Aram dan Roma dalam hal ini mereka tetap mempertahankan budaya helenis di mana bahasa Yunani adalah bahasa internasional, jadi budaya helenis di terpengaruh pada waktu itu dalam gereja.

Vangemeren berkata dalam bukunya bahwa: "Septuaginta yang diterjemahkan itu menjadikan Perjanjian Lama tersedia bagi mereka yang berbahasa Yunani, tetapi juga menjadikan kitab Yahudi sebagai basis untuk dialog dengan orang bukan Yahudi dan membantu menumbuhkan perasaan kesatuan yang lebih besar di antara Yahudi diaspora."22 Penulis simpulkan bahwa dari sinilah muncul orang-orang non-Yahudi percaya kepada pengajaran Yahudi yang telah diberikan oleh Musa dan mereka hidup menurut Hukum Taurat. Guning berkata dalam bukunya bahwa: "Dalam kebudayaan helenisme unsur-unsur dari Timur dan barat, bercampur filsafat dan agama". 23 Penulis simpulkan bahwa dari kebudayaan helenisme inilah ada pendapat yang berbeda-beda sehingga tidak memenuhi apa yang diharapkan oleh budaya tersebut.

Jika dilihat dalam pengaruh helenisme ini maka pengaruh gereja bagi pemikiran (filsafat) itu sangat tinggi yang mengajarkan dengan memakai rasio yang tentang Allah logos $\left(\lambda \circ \gamma_{0} \zeta\right)$. Dampak helenisasi tidak dapat dihindari karena bahasa, literatur, filsafat, adat, dan penemuan ilmiah yang terkait dengan budaya Yunani menantang Yudaisme setiap hari. ${ }^{24}$ Penulis simpulkan bahwa hal ini dampak dari helenisme ini menimbulkan akulturasi sehingga tercatat dalam sejarah bahwa konflik antara Yudaisme dan Paganisme memuncak pada pemerintahan Antiokus yang memaksa orang Yahudi untuk menyembah Zeus dan menajiskan Bait Suci di Yerusalem dengan mengorbankan seekor babi di atas mezbah korban bakaran pada tahun 167 SM.

Stambaugh berkata bahwa: "Sebuah kebiasaan setempat dijemaat di Roma, fermentum melukiskan upaya awal mempersatukan jemaat-jemaat yang beraneka ragam ke

${ }^{21}$ John Stambaugh - David Balck, Dunia Sosial Kristen Mula-Mula, (Jakarta: BPK Gunung Mulia, 2008), 221

${ }^{22}$ Willem Vangemeren, Progres Penebusan, (Surabaya: Momentum, 2016,), 351

${ }^{23}$ Ds. J. J. Guning, Tafsiran Alkitab Surat Galatia, (Jakarta: BPK Gunung Mulia, 2003), 130

${ }^{24}$ Vangemeren, Progres Penebus, 351 
dalam satu persekutuan." 25 Penulis simpulkan bahwa dalam kebudayaan yang helenisme ini membentuk kesatuan yang erat, melalui fermentum di mana ketika uskup merayakan ekaristi, sehingga roti yang telah dikuduskan akan dibagi kepada jemaat sehingga ketika ada perayaan ekaristi maka roti itu akan dicampur pada roti yang akan disajikan.

Dari semua penjelasan di atas maka penulis menyimpulkan bahwa, kebudayaan helenisme ini benar-benar mempengaruhi jemaat mula-mula Roma di mana ada pemikiran filsafat yang cukup terkenal mengombrak abrik kekristenan dan juga memberikan pemikiran-pemikiran yang disesuaikan dengan pemahaman dengan budaya setempat sehingga di situ terjadi akulturasi antar umat Kristen dan dengan helenisme, dan terjadi pertikaian baik dari luar gereja mau pun dari dalam gereja menyerang antara satu dengan yang lain.

\section{KAJIAN EKSEGETIS SURAT ROMA 12: 9-21}

Dalam bagian ini penulis akan mengeksegese beberapa kata penting untuk mendapatkan kajian yang mendalam sehingga dapat dipahami yaitu Hendaklah kasih itu saling mengasihi! memberkati! sehati sepikir! lakukanlah yang baik!

\section{Kasih Itu Saling Mengasihi Ayat 10}

Kata kasih dalam bahasa Yunani $\alpha \gamma \alpha \pi \eta u$ agapen dari kata dasar $\alpha \gamma \alpha \pi \eta$ agape yang artinya kasih, perjamuan kasih. ${ }^{26}$ Dalam kasus noun accusative femineine singuler. Kata benda yang tertuju kepada orang pertama tunggal seperti sifat perempuan pada umumnya. Sedangkan singuler adalah kata yang menunjuk kepada objek. dalam KJV memakai kata yang paling umum digunakan untuk kata kasih adalah agape. Palmer menjelaskan bahwa kasih berarti yang paling tinggi dan yang paling mulia, terjemahan ini cenderung diambil dari sipagtualgita yang menggambarkan kasih Allah kepada manusia dan kasih manusia kepada sesama. ${ }^{27}$ Artinya bahwa kasih lebih tinggi dari pada karakter lainnya yang berhubungan dengan Allah dan sesama manusia.

Moulton menggunakan kata "agape yaitu Love kindly concern, devotedness",28 Artinya kasih, baik/ramah, peduli, sangat setia, sangat penyayang. ${ }^{29}$ Zodhiates mengartikan kata ini secara harafiah berarti "To love, affectionate, good will,

\footnotetext{
${ }^{25}$ Stambaugh - David Balck, Dunia Sosial Kristen Mula-Mula, 201

${ }^{26}$ Strong,S, "Faith", Bible Works 7, 4102

${ }^{27}$ Palmer, “Kasih” Dalam Jd. Douglas (Ed), Ensiklopedi Alkitab Masa Kini Jilid I, (Jakarta: YKBK, 2002), 525

${ }^{28}$ Harolk K. Moulton, The Analitical Greek Lexicon Revised, (American: Zondervan Publishing House, 1977), 2

${ }^{29}$ John M. Echlos, Kamus Inggris Indonesia, (Jakarta: Gramedia Pustaka Utama, 1982), 135-188
} 
benevolence". ${ }^{30}$ Artinya untuk cinta, kehendak baik, kebajikan. Dalam kamus Besar Bahasa Indonesia kata kasih artinya beri; memberi, perasaan sayang, cinta. ${ }^{31}$ Barclay mengatakan dalam bukunya bahwa:

Mengasihi orang lain adalah memandang mereka seperti Allah memandang mereka. Ia tidak melakukan apapun kecuali mencari hal terbaik bagi mereka. Itu berarti membalas kebencian dengan pengampunan, membalas dendam dengan kasih, membalas sikap acuh tidak acuh dengan perhatian menyala yang tidak dapat dipadamkan. ${ }^{32}$

Artinya bahwa kasih yang dimiliki adalah kasih yang tidak pernah memandang status seperti Allah dan tidak membalas kejahatan. Browning dalam bukunya mengatakan bahwa:

Dalam surat-surat Rasul Paulus kasih dengan iman dan pengharapan (1 Korintus 13:13), sebagai karunia Roh Kudus. Kasih itu bukan kasih usaha manusia dan oleh karena itu bukan alasan untuk membanggakan diri (1 Korintus: 13:4), pengorbanan Kristus di kayu salib adalah tanda tertinggi dari kasih Allah (Roma 8:39). Oleh karena itu gaya hidup orang Kristen harus berteladan kepadaNya. ${ }^{33}$

Artinya bahwa kasih yang dimiliki oleh manusia berasal dari Allah melalui kematianNya di atas kayu salib. Brill mengatakan "Kasih seperti kasih terhadap saudara sendiri adalah dasar dan kegenapan kehidupan Kristen. Kasih juga menjadi dasar segala hubungan sosial. Jikalau seseorang mempunyai kasih sedemikian, tentu ia akan berusaha supaya ia tidak menjadi beban bagi orang lain. ${ }^{34}$ Artinya bahwa manusia yang memiliki kasih bisa menepatkan diri dimanapun berada dan bisa menjalin relationship dengan semua orang serta tidak menjadi beban bagi orang lain. Barclay juga mendukung pernyataan Brill bahwa: "Kasih adalah kasih persaudaraan, kasih kepada persekutuan umat Kristen yang kepada Timotius diutus. Sifat kasih yang seperti inilah yang memberikan kualitas kepada seorang hamba Tuhan, ia harus mengasihi orang lain sedemikian rupa sehingga tidak perlu ada kesulitan yang terlalu berat untuk diatasi demi mereka atau tidak ada situasi mengancam yang membuatnya patah semangat. Tidak seorangpun hamba Tuhan bisa melayani dengan baik tanpa ada kasih di dalam hatinya. ${ }^{35}$ Artinya bahwa kasih yang tertanam dalam diri akan menunjukkan kualitas hidup sebagai hamba Tuhan, sebab dalam pelayanan yang dibutuhkan adalah kasih.

\footnotetext{
${ }^{30}$ Spiros Zodhiates, Word Study Dictionari New Testamant, (U.S.A: Amg, 1993), 66

${ }^{31}$ Siswo Prayitno, Hadi Podo, Kamus Besar Bahasa Indonesia, 421

${ }^{32}$ William Barclay, Pemahaman Alkitab Setiap Hari..., 240-241

${ }^{33}$ W.R.F. Browing, Kamus Alkitab, (Jakarta: BPK Gunung Mulia, 2011), 175

${ }^{34}$ J. Wesley Brill, Tafsiran Surat Tesalonika, (Bandung: Yayasan Kalam Hidup, 2008), 66

${ }^{35}$ William Barclay, Pemahaman Alkitab Setiap Hari., 225
} 


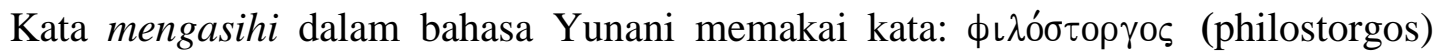

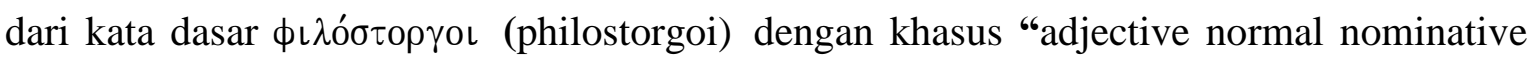
masculine plural no degree". ${ }^{36}$ Kata "nominatif zaman menunjukan bahwa mengasihi itu bukan hanya sesekarang saja tetapi untuk selama-lamanya. Kata Yunani untuk saling mengasihi muncul di sini dalam PB dan khususnya digunakan untuk menggambarkan kasih antara anggota-anggota keluarga. Frase dengan mesra, yang dimaksud di sini adalah keluarga besar orang percaya, dalam terjemahan yang mengatakan 'hendaklah kalian saling mengasihi dengan hangat sebagai saudara-saudara di dalam Kristus dan saling memberi hormat kepada satu dengan yang lain dan terus semangat dalam melayani Tuhan dengan segenap hati. ${ }^{37}$

Dari sudut tata bahasa, ayat ini tetap tergantung dari kata-kata pertama ayat 9. Filostorgia adalah cinta yang mesra. Dalam terjemahan harafiah 10a berbunyi: dalam hal kasih persaudaraan hendaklah kamu bercinta mesra yang satu terhadap yang lain. prohegoumenoi terjemahan 'saling mendahului' dapat juga mengandung arti 'saling mengatasi'. kedua arti ini berdasarkan pemakaian kata dasar hegeisthai arti menghargai, yang menghasilkan terjemahan secara (harafiah), 'dan dalam hormat saling menghargai lebih tinggi'. Jadi anjuran dalam ayat ini tetap merupakan penjabaran kasih yang disebut dalam ayat terdahulu. kasih itu terutama harus diamalkan dalam hubungan antara sesama anggota jemaat (saudara-saudara). Maka dalam hubungan itu harus bagaikan hubungan antara sesama anggota keluarga yang bahagia. Penuh kemesraan, hangat, akrab. Bukan kaku dan menjaga jarak, sehingga di dalam gereja kita mamakai sapaan 'tuan' dan 'nyonya' ${ }^{38}$ Marilah memberanikan diri untuk masuk ke dalam hubungan yang mesra dengan Allah tanpa takut, tetapi dengan keyakinan bahwa kita akan menerima kasih dan menerimanya semakin banyak. ${ }^{39}$

Namun, hubungan antara sesama anggota jemaat tidak hanya ditandai kemesraan. Seharusnya berlaku pula sikap hormat-menghormati. Dalam hal ini berlakulah kaidah bahwa setiap orang Kristen harus menghormati sesamanya anggota jemaat lebih daripada dirinya sendiri. (Itulah makna kata-kata ini, apa pun terjemahan yang kita pilih.) Hal itu tidak berarti bahwa seorang Kristen harus menganggap saudaranya lebih pandai atau berhikmat daripada dirinya sendiri. Maknanya dijelaskan oleh 1 Kororintus 12:22-23. Dalam jemaat, mereka yang kurang terhormat dipandang dari sudut manusia justru harus

\footnotetext{
${ }^{36}$ Bibelworks 7, Minggu 20 Januari Pukul 09:10 Menit

${ }^{37}$ Barclay, Surat Paulus Kepada Jemaat Di Roma, 294-295

${ }^{38}$ End, Tafsiran Alkitab Surat Roma, 676

${ }^{39}$ Henri J.M. Nouwen, Bekal Peziarahan Hidup, (Yogyakarta: Kanisius, 2003),
} 
menerima hormat yang lebih besar. Dengan demikian ditegaskanlah asas perombakan segala nilai manusiawi dalam Kerajaan Allah. Dalam Roma 14 dan 15 Paulus menjabarkan asas saling menghargai lebih tinggi itu dengan cara lain lagi, sebab mengaikatnya dengan masalah hubungan antara golongan kaum 'kuat' dan kaum 'lemah' disitulah bahwa Allah telah menerima orang itu (14:3), dan 'Kristus telah mati untuk dia' (14:15). Kerendahan hati merupakan sifat dasar kehidupan seorang Kristen. ${ }^{40}$

Jadi dapat simpulkan bahwa Timotius dalam pelayanannya harus memiliki kasih sebagai petunjuk kualitas diri yang mengasihi Allah dan manusia tanpa memandang status, serta bisa menepatkan diri dan membawa dampak yang baik dimanapun berada.

\section{Memberkati Ayat 14}

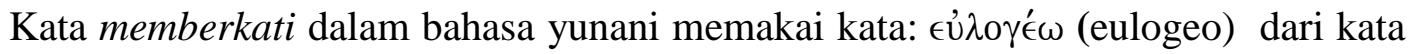
dasar $\epsilon \dot{\lambda} \lambda o \gamma \epsilon \iota \tau \epsilon$ (euvlogeite) bersifat terlalu umum; "verb imperative present active 2nd person plural". ${ }^{41}$ Kata "present menunjukan bahwa memberkati itu secara aktif bukan hanya sekali terus-menerus". LAI menerjemahkan (diokein) (mengejar) tidak berarti

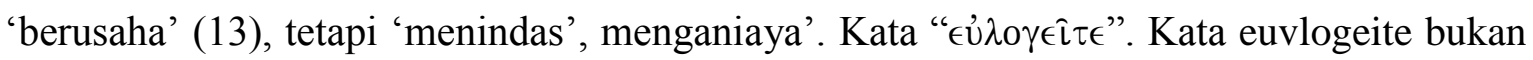
pasif tetapi kata kerja aktif. Sehingga terjemahannya lebih tepat bahwa Dia yang telah mengetahui. Jadi, kata memberkati ini menunjuk kepada sikap seseorang terhadap sesamanya. Artinya bahwa pertama-tama Paulus memberi nasehat mengenai sikap yang harus diambil orang Kristen terhadap siapa yang menganiaya kamu. Pada waktu itu jemaat-jemaat pertama sering mengalami tekanan dari pihak dunia sekeliling. Jadi, apalagi para pekabar injil, termasuk Paulus sendiri dimusuhi dan diserang. Maka jemaat memerlukan nasehat sehubungan dengan sikap yang seharusnya diambilnya dalam keadaan seperti itu. Nasehat yang terdapat di sini sama seperti yang diberikan oleh Tuhan Yesus sendiri menurut Matius 5:44. Maka orang Kristen tidak boleh membalas penganiayaan itu dengan cara mengutuk musuh mereka; mereka malah harus memberkati musuh itu. Dengan demikian mereka benar-benar akan serupa dengan Tuhan mereka, yang mendoakan musuh-musuh-Nya pada waktu Ia tergantung di kayu salib (Lukas 23:34). Bila menafsirkan ayat ini harus ingat bahwa dalam PL dan PB kutuk dan berkat merupakan perkara yang serius. Karena pengucapan berkat sungguh-sungguh membawa kebahagiaan, sedangkan pengucapan kutuk benar-benar membawa celaka. Maka yang Tuhan mau adalah mengenakan manusia baru (Efesus). ${ }^{42}$ Dalam bahasa indonesia sehari-hari

\footnotetext{
${ }^{40}$ End, Tafsiran Alkitab Surat Roma, 676-677

${ }^{41}$ Bibelworks 7, Minggu 20 Januari Pukul 09:20 Menit

${ }^{42}$ End, Tafsiran Alkitab Surat Roma, 681-682
} 
mengatakan bahwa 'Mintalah kepada Allah supaya Ia memberkati orang-orang yang kejam terhadapmu. Ya, minta Allah memberkati mereka, jangan mengutuk'. Artinya bahwa berkatilah siapa yang menganiya kamu. Dalam konteks Alkitab yang memberkati adalah Allah. Dalam bahasa masa kini menyatakan hal yang tersirat itu dalam terjemahan mintalah kepada Allah supaya ia memberkati orang yang menganiaya kamu. Dalam bahasa tertentunya harus dikatakan, berdoalah kepada Allah agar Ia memberkati. Kata berkatilah dan jangan mengutuk: Dalam terjemahannya jangan sampai memberi kesan bahwa Allah bermaksud mengutuk para penganiaya, hendaklah orang Kristen berdoa agar Ia jangan lakukan begitu. Arti ialah bahwa orang Kristen tidak boleh meminta Allah untuk mengutuk orang-orang yang menganiaya mereka. Frase ini pun dapat diterjemahkan, mintalah/ (berdoalah) agar Allah memberkati dan jangan minta agar ia mengutuk. ${ }^{43}$

\section{Sehati Sepikir Ayat 16}

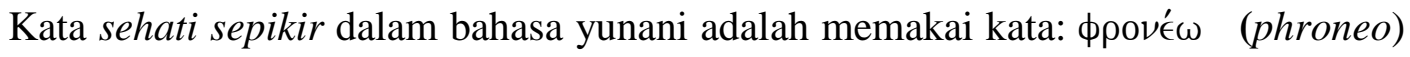

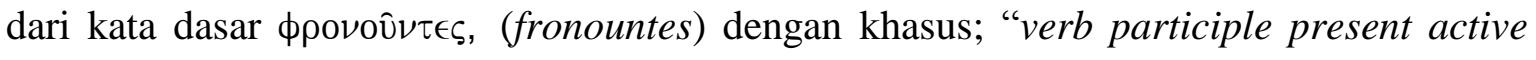
nominative masculine plural". ${ }^{44}$ Kata "kerja present menunjukan bahwa pikirkan hal yang sama kepada satu sama yang lain artinya adalah hiduplah serasi satu sama lain dengan kata lain adalah jangan hidup dengan saling bertengkar, jangan bersengkata; dalam bahasa lain, dapat digunakan ungkapan, seperti hiduplah bersama seperti pohon-pohon dalam hutan. ${ }^{45}$ Jadi, hidup ini harus mulai dengan menyedari bahwa hati kita yang risau merindukan kasih yang sempurna, tidak dapat menemukan kasih seperti itu selain kalau Umat Tuhan mempersatukan diri dengan Dia yang menciptakan umat-Nya. Maka dalam hal ini janganlah memikirkan perkara-perkara yang tinggi: dalam terjemahan BIMK janganlah bersikap tinggi hati, atau janganlah bersikap sombong, tetapi arahkanlah dirimu kepada perkara-perkara yang sederhana arti yang kedua ini dalam terjemahan adalah bertemanlah dengan orang-orang miskin, bersahabatlah dengan orang-orang yang bukan siapa-siapa, atau buatlah orang-orang yang tidak terpandang menjadi teman-temanmu dan janganlah menganggap dirimu sudah pandai. ${ }^{46}$ Dalam bahasa indonesia sehari-hari "hiduplah rukun satu sama lain. Janganlah bersikap tinggi hati, tetapi sesuaikanlah dirimu dengan orang yang rendah kedudukannya. Jangan menganggap diri lebih pandai daripada yang sebenarnya." 47

\footnotetext{
${ }^{43}$ Barclay, Surat Paulus Kepada Jemaat Di Roma (Jakarta: LAI, 2012), 295-296

${ }^{44}$ Bibelworks 7, Minggu 20 Januari Pukul 10:10 Menit

${ }^{45}$ Barclay, Surat Paulus Kepada Jemaat Di Roma, (Jakarta: LAI, 2012), 297

${ }^{46}$ Barclay, Surat Paulus Kepada Jemaat Di Roma, (Jakarta: LAI, 2012), 297-298

${ }^{47}$ Barclay, Surat Paulus Kepada Jemaat Di Roma, 297
} 


\section{Lakukanlah Yang Baik Ayat 17}

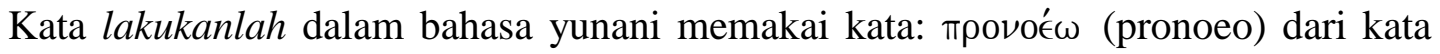

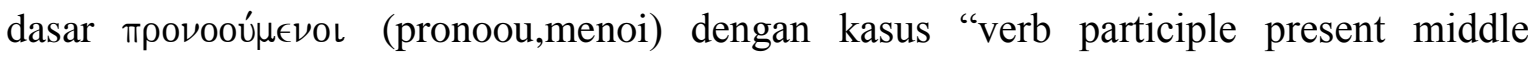
nominative masculine plural". ${ }^{48}$ Kata "kerja present menunjukkan bahwa lakukanlah itu terjadi sedang dikerjakan". ${ }^{49}$ Dalam tafsiran "pronoeisthai" berarti "menaruh perhatian, berupaya, pro mengandung unsur yaitu merencanakan'. Dalam ayat 17-21 Paulus memberi nasehat mengenai sikap terhadap orang yang menurut ukuran manusia adalah musuh. sama seperti ayat 14, begitu juga disini temukan anjuran yang termasuk dalam 1 Tesalonika 5:15 dan 1 Petrus 3:9, serta dalam Kitab Injil (Mat. 5:38). Nasehat ini berakar dalam PL (Amsal. 20:22;24:24:29; Keluaran 23:4). Bahwa Yesus Kristus telah berbuat sesuai dengan asas ini. 'ketika Ia dicaci-maki, Ia tidak membalas dengan mencaci-maki, (1 Petrus 2:23). Karena itu, orang percaya juga tidak boleh membalas kejahatan dengan kejahatan.

Sebaliknya, mereka harus melakukan apa yang baik bagi semua orang. Dalam bahasa aslinya tertulis: di hadapan semua orang. Dapat mengartikannya bahwa dalam pandangan menurut pendapat semua orang meskipun oran banyak senang berbuat segala macam kejahatan (1:18-32), mereka sering melihat kebaikan dalam orang lain. Maka orang Kristen harus berupaya (di sini malah dipakai kata kerja yang dapat berarti 'merencanakan untuk melakukan apa yang oleh semua orang pandang baik. Dengan demikian nama Tuhan dipuji dan jemaat-Nya dihormati. Dengan cara itu juga kelompok minoritas kecil dapat berpengaruh besar dalam masyarakat luas.

Paulus bercara di sini mengenai pergaulan antara orang perseorangan. Pada masa ia menulis Surat Roma ini sama sekali belum ada penguasa yang masuk Kristen. Jadi, di sini ia tidak berbaksud hendak memberi nasihat kepada pemerintah. Jadi tidak boleh begitu saja menyamakan kedudukan orang percaya dengan kedudukan pemerintah sebagai hamba Allah. $^{50}$

\section{MAKNA HIDUP DALAM KASIH MENURUT RASUL PAULUS BERDASARKAN ROMA 12:9-21}

Sebelum membahas lebih jauh dampak makna hidup Rasul Paulus dalam kasih berdasarkan kajian Teologis, maka perlu diketehui bahwa Pasal ini merupakan pasal Alkitab yang klasik mengenai masalah makna hidup dalam kasih. sebagian besar orang Yahudi percaya akan adanya kasih (yaitu hukum Taurat) bagi bangsa Yunani jiwalah yang

\footnotetext{
${ }^{48}$ Bibelworks 7, Minggu 20 Januari Pukul 10:25 Menit

${ }^{49}$ End, Tafsiran Alkitab Surat Roma, 685

${ }^{50}$ End, Tafsiran Alkitab Surat Roma, (Jakarta: BPK Gunung Mulia, 2010), 685-686
} 
kekal, justru gagasan mengenai menuntut kasih itulah yang tampaknya sangat ganjil bagi mereka (Matius 22:36-39; Ulangan 6:5). ${ }^{51}$

\section{Mengasihi Allah.}

Kalau mereka harus mengasihi dan mengampuni musuh-musuh mereka, tidak mengherankan pentingnya kasih di dalam kelompok murid-murid-Nya sendiri. Ia menyebutnya sebagai "perintah baru" kalau mereka saling mengasihi maka semua orang akan tahu bahwa mereka adalah murid-muridNya (Yoh. 13:34-35). Tentu kasih bukan hanya perasaan hangat bagi sesama rekan. Yesus memberikan "perintah batu" ini tepat setelah ia memberikan suatu contoh nyata yang mencolok tentang arti kasih. ia baru saja membasuh kaki semua muridNya. Ia Tuhan mereka telah melakukan tugas seorang hamba. ${ }^{52}$ Tidak ada tempat bagi rasa tinggi hati dalam likungan Yesus. Pelayanan dengan rendah hati tanpa mempedulikan kepentingan sendiri, itulah tanda kebesaran. Berusaha merebut kedudukan sama sekali tak mungkin. Allah harus meduduki tempat pertama dalam kesetiaan seorang murid. Kehidupan seorang murid Yesus harus tertuju kepada Allah. $^{53}$

\section{Mengasihi Sesama Manusia}

Tuhan berfirman kepada Musa: berbicaralah kepada segenap jemaah dan katakan kepada mereka kuduslah kamu sebab Aku Tuhan Allahmu kudus. Janganlah engkau membenci saudaramu di dalam hatimu, tetapi engkau harus berterus terang menegor orang sesamamu dan janganlah mendatangkan dosa kepada dirimu karena dia. Janganlah engkau menuntut balas dan janganlah menaruh dendam terhadap orang-orang sebangsamu melainkan kasihilah sesamamu manusia seperti dirimu sendiri Akulah Tuhan. ${ }^{54}$

Dalam Perjanjian Lama saja diajarkan janganlah engkau membenci saudaramu di dalam hatimu, tetapi engkau harus berterus terang menegor orang sesamamu dan janganlah engkau menuntut balas, dan janganlah menaruh dendam terhadap orang-orang sebangsamu, melainkan kasihilah sesamamu manusia seperti dirimu sendiri Akulah Tuhan (Im. 19:17-18). Apabila kamu mengasihi orang yang mengasihi kamu, apakah upahmu bukankah pemungut cukai juga berbuat demikian dan apabila kamu hanya memberi salam kepada saudara-saudaramu saja, apakah lebuhnya dari pada perbuatan orang lain bukankah orang yang tidak mengenal Allah pun berbuat demikian Mat. 5:46-47.

${ }^{51}$ Malcolm Brownlee, Tugas Manusia Dalam Dunia Milik Tuhan, (Jakarta: BPK Gunung Mulia, 2011), 24-27

${ }_{53}^{52}$ R. T. France, Yesus Sang Radikal, (Jakarta: BPK Gunung Mulia, 2004), 55

${ }^{53}$ France, Yesus Sang Radikal, , 55-56

${ }^{54}$ Subroto Widjojo, Mengasihi Musuh, (Bersumber: Http: Www Karismatik Katolik Org Mengasihi-Musuh.Html Diunduh Rabu 2 Oktober 2019), 
Aku memberikan perintah baru kepada kamu saling mengasihi sama seperti Aku telah mengasihi kamu demikian pula kamu harus saling mengasihi. Dengan demikian semua orang akan tahu, bahwa kamu adalah murid-murid-Ku, yaitu jikalau kamu saling mengasihi (Yoh. 13:34-35); barangsiapa tidak mengasihi, ia tidak mengenal Allah, sebab Allah adalah kasih Yoh. 4:8. ${ }^{55}$ Jadi penulis simpulkan bahwa janganlah membalas kejahatan dengan kejahatan lakukanlah yang baik kepada semua orang. Wanita, orang yang hidup dalam kasih Allah pastinya ia memiliki perkataan yang penuh kasih. Kita tahu bahwa sebuah perkataan itu punya kuasa. Kuasa untuk memberkati bahkan kuasa untuk mengutuk. Namun, yang Tuhan Yesus ajarkan ialah agar setiap kita memiliki perkataan yang dapat membangun bahkan memberkati, perkataan yang penuh kasih terhadap seorang akan yang lain. Mari saat ini coba renungkan, perkataan seperti apa saja yang sudah keluar dari mulut ini. Apakah perkataan yang membangun, memberkati, perkataan positif ataukah perkataan yang menjatuhkan, perkataan yang penuh dengan sungut-sungut, kekecewaan, keputusasaan atau kebencian? Mari Wanita Allah, ambillah keputusan untuk mengubah perkataan kita. Biarlah perkataan yang keluar itu hanya untuk memberkati bahkan membangun, memberi semangat, mendorong, menguatkan bahkan menghidupkan. Karena setiap perkataan yang keluar dari mulut harus dapat kita pertanggungjawabkan di hadapan Tuhan. "Tetapi Aku berkata kepadamu: Setiap kata sia-sia yang diucapkan orang harus dipertanggungjawabkannya pada hari penghakiman." Matius 12:36.

Hendaklah perkataan Kristus diam dengan segala kekayaannya di antara kamu, sehingga kamu dengan segala hikmat mengajar dan menegur seorang akan yang lain dan sambil menyanyikan mazmur, dan sambil menyanyikan mazmur dan puji-pujian dan nyanyian rohani, kamu mengucap syukur kepada Allah di dalam hatimu.

\section{PENUTUP}

Surat Roma ini di tulis Rasul Paulus, sekitar tahun 57 M di Korintus (Akhayal) karena pada waktu itu ada rencana orang-orang Yahudi ingin membunuh Paulus (Kis. 20:2) sehingga ia menyingkir ke kota Korintus (Akhayal) untuk berdiam diri, di sana ia menulis surat ini mencatumkan teologi yang sangat sistematis dan mendalam seperti sebuah intan yang tersembunyi. Surat Roma ditujukan kepada jemaat di Roma, didirikan oleh Yahudi diaspora, sejarah mencatat bahwa jemaat Roma didirikan oleh Yahudi pada

${ }^{55}$ Revi Halim, Panggilan Untk Mengasihi, Grace Depth, (2017), Bersumber Http://Www.Gracedepth.Com/Panggilan-Untuk-Mengasihi, Diunduh Rabu 2 Oktober 2019 
hari pentakosta di Yerusalem sehinga orang yang menerima Kristus dapat bertobat mereka adalah perdana gereja mula-mula di Roma.

Di dalam 49 M maka ada penganiayaan yang muncul di kekaisaran Roma atas perintah Kaisar Kladius karena ada pengajaran baru tentang Kristus. Sehingga pada waktu itu juga seluruh orang Yahudi di usir dari Roma. Karena mereka semangat memeritakan Injil sehingga ada orang juga orang non-Yahudi yang bertobat. Orang Kristen non-Yahudi semangat juga memberitakan Injil kepada orang-orang Romawi sehingga berjalannya waktu maka ada banyak jemaat orang Romawi yang percaya kepada Kristus. Dan Ketika kematian Kladius di tahun 54 maka diijinkan kembali orang-orang Yahudi masuk dan tinggal di kota Roma dan pada tahun 64 M Kaisar Nero membantai oran-orang Yahudi dan orang Kristen. Darah orang martir adalah benih gereja sehingga berjalannya waktu maka kerajaan itu berbalik dari penyembahan berhala menjadi percaya kepada Kristus.

Gereja mula-mula dipengaruhi oleh kaum Helenisme yang telah berpengaruh pada waktu itu, dan bahasa yang dipakai adalah bahasa Yunani sebagai Internasional yang dipakai oleh semua kaum suku dan bangsa.

Percaya kepada Kristus maka darahnya yang kudus akan menyucikan diri setiap orang dari dosa sehingga di hadapan Allah orang itu dinyatakan benar. Jadi jika Allah membenarkan orang yang tidak pura-pura dalam kasih maka walau pun ia dikandung dalam dosa maka orang tersebut tetap akan dinyatakan benar. Dan jika sudah dinyatakan benar maka akhir dari orang percaya adalah Hidup dalam kasih di sini berbicara kepada sesama dan hubungannya denga Tuhan, sehingga Kristus menjadi yang sulung diantara mereka.

Makna hidup dalam kasih adalah kasih sayang, cinta, suka dalam kasih sayang, suka Allah, tidak ada unsur manusia di dalamnya karena manusia telah berdosa dan tidak berdaya lagi. Hidup dalam kasih Allah dilakukan atas kedaulatan Allah dan bukan atas dasar perbuatan manusia. Karena Allah telah mengasihi manusia maka manusia tidak ada alasan tidak memiliki kasih itu, Sebab karena Allah akan bekerja dalam hidup manusia seningga orang-orang yang telah ditentukan untuk menjadi anak-anak Allah dan menjadi ahli waris kerajaan Sorga bersama dengan AnakNya sehingga Anak menjadi yang sulung di antara semua orang percaya.

Allah memberkati umat-Nya artinya bahwa manusia pasif dan Allah yang aktif memberkati segala apa yang umat-Nya lakukan dalam segi apapun itu, jika Allah memberkati umat-Nya maka walau pun orang tersebut tidak akan berkekurangan suatu apapun itu, sehingga berkat-berkat yang tercurah bagi orang percaya menjadi milik 
bagiannya dan sebagai wujud kasih orang percaya ia mengasihi Allah dengan segenap hati dan mengasihi sesama seperti yang Tuhan Yesus perintahkan bagu umat-Nya.

Hidup memang perjalanan yang harus diselesaikan untuk maju berjuang. Sebagai orang percaya harus semangat juang tinggi untuk hidup tetap bersama Tuhan. hidup perjalanan penuh liku-liku yang dialami mengungkapkan totalitas perjuangan sampai kedatangan Tuhan Yesus Kristus ke dua kalinya, sehingga sampai pada tujuan. Paulus orang percaya yang di pakai Tuhan Yesus sebagai pelantara untuk membagikan kasih Kristus dan Paulus memakai kasih dengan caranya ia melakukan kasih itu sendiri dan ia menjadikan dirinya sebagai pengasih bagi semua orang agar dapat masuk kalangan orang Yahudi. Mahasiswa/i atau sebagai hamba Tuhan diwajibkan melakukan kasih seperti yang dipakai Rasul Paulus itu sendiri ia sebagai pengasih dan mahasiswa/i atau hamba Tuhan menjadi pengasih juga kepada semua orang kapan dan dimana pun berada.

Orang percaya yang sudah hidup dalam kasih tidak mencemarkan hidupnya dalam dosa, sehingga sasaran yang diinginkan oleh Tuhan Yesus Kristus dalam hidup ini nama Tuhan dimuliakan saja, Paulus seorang yang luar biasa di pakai Tuhan karena ketaatannya pada Tuhan Yesus Kristus. Paulus adala seorang yang hidup di dalam Tuhan Yesus Kristus, maka apa yang Paulus kerjakan semuanya berhasil karena penyertaan Tuhan Yesus Kristus tidak pernah lepas dari hidupnya.

Hidup dalam kasih tidak lepas dari pimpinan Tuhan, maka sebagai umat Tuhan Yesus Kristus di haruskan mengkedepankan Tuhan Yesus Dalam segala hal keinginannya, sehingga dalam hal itu tidak jatuh dalam dosa dan hidup berbahagia bersama Tuhan Yesus Kristus sampai ke datangan Tuhan Yesus Kristus yang ke dua kalinya, sehingga apapun yang terjadi dalam hidup ini tidak pernah sia-sia begitu saja tetapi ada kekutan dari pada Tuhan Yesus Kristus itu sendiri. Soli Deo Gloria 


\section{DAFTAR PUSTAKA}

Beownlee, Malcolm. (2011). Tugas Manusia Dalam Dunia Milik Tuhan, Jakarta: BPK Gunung Mulia.

Brill, J. Wesley. (2008). Tafsiran Surat Tesalonika, Bandung: Yayasan Kalam Hidup.

Browing, W.R.F. (2011). Kamus Alkitab, Jakarta: BPK Gunung Mulia.

Dewi, Legiyani. (2017). Kumpulan Cerpek Kisah-Kasih Di Dunia, Jakarta :Guepedia Publisher.

Drane, John, Memahami Perjanjian Baru, Jakarta: BPK Gunung Mulia.

Echols, John M. (1982). Kamus Inggris Indonesia, Jakarta: Gramedia Pustaka Utama.

End, Th Van Den. (2010). Tafsiran Surat Roma, Jakarta: BPK Gunung Mulia.

France, R. T. (2004). Yesus Sang Radikal, Jakarta: BPK Gunung Mulia.

Guning, J. J. (2003). Tafsiran Alkitab Surat Galatia, Jakarta: BPK Gunung Mulia.

Hagelberg, Dave. (2013). Tafsiran Roma, Bandung: Kalam Hidup.

Hakh, Samuel Benyamin. (2010). Perjanjian Baru, Bandung: Bina Media Informasi.

Halim, Revi. (2017). Panggilan Mengasihi Musuh, Grace Depth, Http://Www.Gracedepth.Com/Panggilan-Untuk-Mengasihi.

Indrayana, Stefanus. (2007). Best Live Menjalani Hidup Bahagia Penuh Makna, Jakarta: Pt Elex Media Komputindo.

J., Darminta. (2006). Pratinjau, Penegasan Panggilan, Yogyakarta :Kanisius.

Jaffray, R. A. (2007). Tafsiran Surat Roma, Bandung: Kalam Hidup.

Margana, P. Tri. (2009). 50 Kalimat Inspiratif Rasul Paulus Untuk Pengembangan Diri. Yogyakarta: Kanisius.

Martadiatmadja, Bs. (1982). Hidup Dalam Roh, Yogyakarta: Kanisius.

Moulton, Harolk K. (1977). The Analitical Greek Lexicon Revised, American: Zondervan Publishing House.

Nouwen, Henri J.M. (2003). Bekal Peziarahan Hidup, Yogyakarta: Kanisius.

Odop, Nistain. (2013). 55 Wasiat Cinta Dan Kehidupan, Jakarta :Elex Media Komputindo.

Olla, Paulinus Yan, Dipanggil Menjadi Saksi Kasih, Yogyakarta: Kanisius.

Palmer. J.D. Douglass (ed.) (2002). Ensiklopedi Alkitab Masa Kini Jilid I, Jakarta: YKBK.

Prayitno, Siswo., Hadi Podo, (....). Kamus Besar Bahasa Indonesia. 
Stambaugh, John dan David Balck (2008). Dunia Sosial Kristen Mula-Mula, Jakarta: BPK Gunung Mulia.

Strong's, Bible Works 7, CD-ROM.

Sumartono. (2004). Komunikasi Kasih Sayang, Jakarta: Pt Elex Media Komputindo.

Vangemeren, Willem. (2016). Progres Penebusan, Surabaya: Momentum.

Widjojo, Subroto. (....) Mengasihi Musuh, Http: Www Karismatik Katolik Org MengasihiMusuh.Html.

Zodhiates, Spiros. (1993). Word Study Dictionary New Testamant, U.S.A: Amg. 